\title{
Research production in high-impact journals of contemporary neuroscience: A gender analysis
}

\author{
Julio González-Álvarez ${ }^{\mathrm{a}, *}$, Teresa Cervera-Crespo ${ }^{\mathrm{b}}$ \\ a Department of Basic and Clinical Psychology and Psychobiology, University Jaume I of Castellón, Spain \\ b Department of Basic Psychology, University of Valencia, Spain
}

\section{A R T I C L E I N F O}

\section{Article history}

Received 15 September 2016

Received in revised form 22

December 2016

Accepted 22 December 2016

Available online xxx

\section{Keywords:}

Neuroscience

Gender

Women

Scientific production

Collaboration patterns

Scientific impact

\begin{abstract}
A B S T R A C T
Neuroscience or Neural Science is a very active and interdisciplinary field that seeks to understand the brain and the nervous system. In spite of important advances made in recent decades, women are still underrepresented in neuroscience research output as a consequence of gender inequality in science overall. This study carries out a scientometric analysis of the 30 neuroscience journals (2009-2010) with the highest impact in the Web of Science database (Thomson Reuters) in order to quantitatively examine the current contribution of women in neuroscientific production, their pattern of research collaboration, scientific content, and the analysis of scientific impact from a gender perspective. From a total of 66,937 authorships, gender could be identified in 53,351 (79.7\%) of them. Results revealed that $67.1 \%$ of the authorships corresponded to men and $32.9 \%$ to women. In relative terms, women tend to be concentrated in the first position of the authorship by-line (which could be a reflection of new female incorporations into neuroscience research publishing their first studies), and much less in the last (senior) position. This double pattern suggests that age probably plays a role in (partly) explaining gender asymmetry, both in science in general and in neuroscience in particular.
\end{abstract}

(C) 2016 Published by Elsevier Ltd.

\section{Introduction}

Despite progress in recent decades, women are still underrepresented in science. Large-scale analyses reveal that global gender disparities persist in different scientific fields. Recently, Larivière, Ni, Gingras, Cronin and Sugimoto (2013) presented a worldwide bibliometric analysis of more than 5 million research and review articles, including more than 27 million authorships, and they found that, globally, women represent fewer than $30 \%$ of scientific authorships. West, Jacquet, King, Correll and Bergstrom (2013) carried out an analysis based on the JSTOR corpus, which comprises more than 8 million scientific documents, and they again revealed that important gender inequities remain in the current research production. Official reports from international organizations reach similar conclusions. The UNESCO Science Report (UNESCO, 2015) states that worldwide only $28 \%$ of researchers are women. The last issue of She Figures (European Commission, 2016), the official report on gender equality in research and innovation in Europe, recently concluded that we are far from achieving gender parity, and that women represent only one third of European researchers. In the foreword of a previous issue, Marie Geoghecan-Quin, the European Commissioner for Research, Innovation and Science, stated, "the figures do show us that some gaps have been reducing slowly over recent years, but gender imbalance in research is not a self-correcting phenomenon and so we must redouble our efforts" (European Commission, 2013, p. 3).

Empirical evidence shows that gender inequality is not confined to research output. Although in many countries the proportion of female undergraduates is equal to or higher than that of male undergraduates (OECD, 2015a; UNESCO 2015), women occupy fewer positions as full professors, and there is an imbalance in hiring, promotion, earnings and grant funding (for a review see e.g. Shen, 2013; UNESCO, 2015). The causes of this imbalance are probably complex, and they do not respond to a

\footnotetext{
* Corresponding author at: Department of Basic and Clinical Psychology and Psychobiology, University of Jaume I, Av. Sos Baynat s/n, 12071, Castellón de la Plana (Castellón), Spain.

Email address: gonzalez@psb.uji.es (J. González-Álvarez)
} 
single reason, but we cannot discard the existence of certain (sometimes subtle) gender biases within science and academia. In an elegant double-blind experiment, Moss-Racusin, Dovidio, Brescoll, Graham, \& Handelsman (2012) identified faculty's subtle gender biases toward female students. The authors asked 127 professors from six American research-intensive universities to review a job application for a laboratory manager position. The application was identical for all professors, and it was randomly assigned the name of a (fictitious) male or female student. Results demonstrated that the "male" applicants were rated as more competent and hireable than the identical "female" applicants, and they were offered a higher salary and more career mentoring. A mediation analysis revealed that the female student was less likely to be hired because she was perceived as less competent. Interestingly, the gender of the professors was unrelated to the judgments, and women exhibited the same gender bias as their male colleagues.

In addition to large-scale studies about global gender inequality in science, recent work has focused the gender analysis on specific fields, such as nanoscience and nanotechnology (Sotudeh \& Khoshian, 2014), computing research (Cavero, Vela, Cáceres, Cuesta, \& Sierra-Alonso, 2015), software engineering (Vela, Cáceres, \& Cavero, 2012), materials science (Mauleón \& Bordon, 2006), medical literature (Jagsi et al., 2006), or psychology (Barrios, Villarroya, \& Borrego, 2013). Neuroscience, or the scientific study of the brain and nervous system, is a very active and expanding research field that, according to the category description from Web of Science, "covers resources on all areas of basic research on the brain, neural physiology, and function in health and disease. The areas of focus include neurotransmitters, neuropeptides, neurochemistry, neural development, and neural behavior. Coverage also includes resources in neuro-endocrine and neuro-immune systems, somatosensory system, motor system and sensory motor integration, autonomic system as well as diseases of the nervous system" (Web of Science, Science Citation Index Expanded, Scope notes, 2014). It is therefore an interdisciplinary field that collaborates with many other areas and has an increasing impact on contemporary science and human society. Several scientometric analyses without gender distinctions have focused on the study of neuroscience production in different countries, such as India, Italy, Sweden or China, (e.g., Bala \& Gupta, 2010; Berardelli, Defazio, Mancardi, \& Messina, 2005; Glänzel et al., Danell, \& Person, 2003; Xu, Chen, \& Shen, 2008), but to our knowledge no publication has performed a quantitative analysis of women's participation in contemporary neuroscience.

For decades, women have contributed in a significant way to the development of neurosciences (Finger, 2002), but a significant gender gap still persists today. In 2006, an editorial of the influential journal Nature Neuroscience complained that only one in every five papers published in its pages had a female corresponding author, and the authors of the editorial wondered if this asymmetry was simply a reflection of reality or if "it could also contribute to perpetuating the problem" (Nature Neuroscience, 2006; p. 853). Since the creation of Women in Neuroscience (WIN) in 1980, an international organization "whose major goal is to promote the professional advancement of women neuroscientists" (Haak, 2002; p.70), there has been a strong interest in fostering their contribution to today's neuroscience. The Society for Neuroscience considers this goal a priority, and it currently devotes efforts and additional resources to increasing women's participation in neuroscience, both in research and academia.

Given the importance of knowing what women's representation is within the brain sciences, we present a bibliometric analysis of the most influential neuroscience journals in order to quantitatively examine the current participation of women in scientific production in this research field. To accomplish this objective, the scientific production, the pattern of research collaboration, the content, and the scientific impact (or the number of citations a paper receives) are analyzed from a gender perspective.

\section{Methodology}

\subsection{Databases and gender identification}

This study was based on Thomson Reuters' Web of Science database. The 30 journals with the highest impact factor in the NEUROSCIENCES subject category were selected from the Journal Citation Reports (Journal Citation Reports (JCR) Edition, 2014) (see Table 1). The impact factor of a scientific journal is a measure that indicates the average number of citations received by studies published in that journal, and it reflects the relative importance of journals within its field. Despite its criticisms, the citation frequency reveals a journal's relevance to its end users, particularly when the readers are primarily researchers (Saha, Saint, \& Christakis, 2003). In the biomedical field, the correlation between impact factor and journal quality rated by field researchers is strong (Saha et al., 2003). Consequently, our sample included a broad selection of the most important and influential journals of the neuroscience field. All the articles and reviews from 2009 to 2010 were extracted in text format and preprocessed through the BibExcel software (Persson, Danell, \& Wiborg-Schneider, 2009) in order to perform the subsequent bibliometric analyses with the BIbExcel and Microsoft Excel 2010 programs. We chose these two years because they are relatively recent and, at the same time, far enough in the past to allow us to study the citations received by papers published in that time period. Records from one journal (Molecular Psychiatry) were subsequently excluded from the analyses because most of its papers (more than 60\%) did not provide authors' first names, only their initials, making it impossible to assign a gender to the authorships.

The Web of Science (WoS) database, like most scientific databases, does not provide the authors' gender. However, in 2008 the WoS began to include the authors' full names (field tag AF: Author Full Name), although a small proportion of records still display only the authors' initials. After a preprocess of normalization that eliminated initials accompanying given names and replaced hyphens with spaces, all authors' first names were matched through GenderChecker, a database that includes 97,500 
Table 1

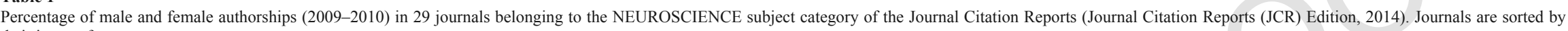
their impact factor.

\begin{tabular}{|c|c|c|c|c|c|c|c|c|}
\hline Journals & Impact Factor & Papers & Authorships & Known Gender & Male Authorships & $\%$ & Female Authorships & $\%$ \\
\hline Nature Reviews Neuroscience & 31.43 & 138 & 337 & 292 & 215 & 73.6 & 77 & 26.4 \\
\hline Trends In Cognitive Sciences & 21.97 & 128 & 321 & 281 & 221 & 78.6 & 60 & 21.4 \\
\hline Behavioral and Brain Sciences & 20.77 & 18 & 36 & 33 & 28 & 84.8 & 5 & 15.2 \\
\hline Annual Review of Neuroscience & 19.32 & 38 & 89 & 81 & 70 & 86.4 & 11 & 13.6 \\
\hline Nature Neuroscience & 16.10 & 416 & 2563 & 2032 & 1395 & 68.7 & 637 & 31.3 \\
\hline Neuron & 15.05 & 575 & 3271 & 2540 & 1813 & 71.4 & 727 & 28.6 \\
\hline Trends in Neurosciences & 13.56 & 132 & 373 & 322 & 241 & 74.8 & 81 & 25.2 \\
\hline Acta Neuropathologica & 10.76 & 244 & 1787 & 1504 & 977 & 65.0 & 527 & 35.0 \\
\hline Biological Psychiatry & 10.23 & 621 & 4516 & 3784 & 2303 & 60.9 & 1481 & 39.1 \\
\hline Progress in Neurobiology & 9.99 & 143 & 488 & 388 & 252 & 64.9 & 136 & 35.1 \\
\hline Annals of Neurology & 9.98 & 365 & 3318 & 2753 & 1816 & 66.0 & 937 & 34.0 \\
\hline Journal of Pineal Research & 9.60 & 180 & 1057 & 681 & 391 & 57.4 & 290 & 42.6 \\
\hline Brain & 9.20 & 569 & 4989 & 3990 & 2608 & 65.4 & 1382 & 34.6 \\
\hline Neuroscience and Biobehavioral Reviews & 8.80 & 226 & 730 & 592 & 378 & 63.9 & 214 & 36.1 \\
\hline Cerebral Cortex & 8.67 & 539 & 2731 & 2145 & 1478 & 68.9 & 667 & 31.1 \\
\hline Sleep Medicine Reviews & 8.51 & 72 & 238 & 216 & 144 & 66.7 & 72 & 33.3 \\
\hline Social Cognitive and Affective Neuroscience & 7.37 & 91 & 448 & 376 & 234 & 62.2 & 142 & 37.8 \\
\hline Neuropsychopharmacology & 7.05 & 457 & 2899 & 2432 & 1483 & 61.0 & 949 & 39.0 \\
\hline Frontiers in Neuroendocrinology & 7.04 & 70 & 237 & 199 & 103 & 51.8 & 96 & 48.2 \\
\hline Neuroscientist & 6.84 & 95 & 227 & 186 & 133 & 71.5 & 53 & 28.5 \\
\hline Current Opinion in Neurobiology & 6.63 & 196 & 426 & 344 & 252 & 73.3 & 92 & 26.7 \\
\hline Molecular Neurodegeneration & 6.56 & 115 & 679 & 523 & 334 & 63.9 & 189 & 36.1 \\
\hline Neuroimage & 6.36 & 1692 & 10,018 & 7697 & 5640 & 73.3 & 2057 & 26.7 \\
\hline Journal of Neuroscience & 6.34 & 3205 & 17,868 & 14,203 & 9572 & 67.4 & 4631 & 32.6 \\
\hline Glia & 6.03 & 322 & 1823 & 1313 & 777 & 59.2 & 536 & 40.8 \\
\hline Human Brain Mapping & 5.97 & 500 & 3070 & 2553 & 1765 & 69.1 & 788 & 30.9 \\
\hline Brain Behavior and Immunity & 5.89 & 286 & 1580 & 1247 & 710 & 56.9 & 537 & 43.1 \\
\hline Journal of Psychiatry \& Neuroscience & 5.86 & 79 & 518 & 409 & 270 & 66.0 & 139 & 34.0 \\
\hline Brain Structure \& Function & 5.62 & 78 & 300 & 235 & 173 & 73.6 & 62 & 26.4 \\
\hline TOTAL & & 11,590 & 66,937 & 53,351 & 35,776 & 67.1 & 17,575 & 32.9 \\
\hline
\end{tabular}


worldwide names classified as male, female or unisex (acquired from http://genderchecker.com/). In order to increase the number of observations, unisex names were matched with the 1990 US Census, which presents lists of given names and their frequencies associated with males and females from the US population. When a name classified as unisex by GenderChecker presented a rate above $90 \%$ vs. $10 \%$ associated with a specific gender in the US Census, the name was finally classified as belonging to that gender (Larivière et al., 2013). For example, 'Aaron' appeared in the US Census 7209 times linked to men and 64 times linked to women $(99.1 \%$ vs. $0.9 \%)$; therefore, it was considered as a male name. Conversely, the name 'Carmen' accounted for 6210 women and 330 men (95\% vs. 5\%) and, consequently, was classified as a female name.

\subsection{Variables studied}

We studied the following variables in relation to the gender of the researchers who published in the selected journals during 2009-2010: number of authorships; number of authors (individuals); number of papers published by each author; geographical origin of authors ( $\mathrm{C} 1$ field of WoS database); pattern of collaboration in co-authorship, including the national vs. international levels of collaboration and the analysis of author order in the by-line of each publication; content analysis through the analysis of the keywords extracted from the papers (ID field); and scientific impact measured as the number of citations received by each paper (TC field or Times Cited).

\subsection{Procedure}

After identifying the gender of the authorships of each publication, each variable studied was extracted from the Thomson Reuters Web of Science database using the BibExcel program (Persson et al., 2009). This software is a toolbox for bibliometricians that creates a file in which the values of an extracted variable are associated with each individual paper (identified with a number). Finally, the values of all the variables studied were combined and entered in a master Excel database to perform the first bibliometric analyses.

\subsection{Analysis of data}

Statistical analyses of the bibliometric parameters were performed with SPSS v.18 and Microsoft Excel 2010. In order to analyze contingencies of one categorical variable (e.g., gender: male vs. female authorships), we applied the Pearson Chi-square test contrasting observed and expected frequencies according to the null hypothesis (no gender disparities). To analyze the relationship between two categorical variables (e.g., gender and USA/EU origin of authorships), we applied the Chi-square test and used Cramer's $V$ to determine the effect size or strength of the association. The standard interpretation of Cramer's $V$ for one degree of freedom $(d f)$ is: $0.10=$ small, $0.30=$ medium and $0.50=$ large; for two $d f: 0.07=$ small, $0.21=$ medium and $0.35=$ large $($ Cohen 1988; Gravetter \& Wallnau, 2012).

When the dependent variable was continuous (e.g., number of papers published by each author), an ANOVA (analysis of variance) was carried out on the factors studied, and we used Cohen's d to calculate the effect size. Cohen's $d$ is a statistic conventionally used to indicate the standardized difference between two means. According to Cohen's guidelines (1988) for effect sizes, the values of $\mathrm{d}$ are interpreted as follows: $0.20=$ small, $0.50=$ medium and $0.80=$ large.

\subsection{Validation study}

To test the accuracy of our data, we followed a similar procedure to Larivière et al. (2013). These authors selected a random sample of 5000 authorships (less than $0.02 \%$ ) from a total of 27,329,915 authorships to manually check their gender identity. We randomly selected 1\% (670) from the total of 66,937 authorships and identified the gender of each author by locating some biographical information or a photo on the internet. After several attempts, seven of the total number of authorships could not be identified. The remaining 663 authorships were 441 males $(66.5 \%)$ and 222 females $(33.5 \%)$, yielding a proportion very close to the overall rate of $35,776(67.1 \%)$ males and 17,575 (32.9\%) females. The difference between the observed frequencies in the validation study (441 males, 222 females) and the expected frequencies according to the overall rate (445 males, 218 females) was not significant, $\chi^{2}(1)=0.10 ; p=0.747$.

\section{Results}

\subsection{Scientific production}

A total of 11,590 papers (10,027 articles and 1563 reviews) published in 2009-2010 were obtained from the 29 journals analyzed (see Table 1). They were signed by 66,937 authorships, making an average of 5.78 authors/paper. After excluding the authorships with only initials, unisex or unmatched given names with the GenderChecker database, 53,351 (79.7\%) items with known gender (male, female) were obtained (henceforth, the percentages of female or male authorships will always refer to the 
known-gender total). ${ }^{1}$ The total number of authorships with known gender included 35,776 (67.1\%) men and 17,575 (32.9\%) women $^{2}$ (Table 1); that is, female authorships are approximately one third of all authorships in the selected neuroscience journals. Applying the Chi square test, the difference between male and female authorships was statistically significant, $\chi^{2}(d f=1)=3,197.76 ; \mathrm{p}<0.0001 ;$ Cramer's $V=0.173 .^{3}$

The geographical location of each author's institution was obtained by extracting the institutional information provided by each paper (C1 field). ${ }^{4}$ Table 2 presents the distribution of the authorships according to their gender and country, sorted by the total number of authorships in descending order. The main scientific producer country, the United States of America (USA), shows a percentage of female authorships of $32.5 \%$ in neuroscience. With regard to the neuroscience production of the European Union (EU), we added the data from all the EU countries and obtained a percentage of $34.2 \%$ of female authorships, which represents $1.7 \%$ more than the percentage of female authorship in the United States of America. This difference is small but significant; applying a Chi-square test to the data for the USA (15,661 males; 7534 females) and the EU (14,165 males; 7351 females), we obtained $\chi^{2}(1)=14.26 ; \mathrm{p}=0.0002$; Cramer's $V=0.018$.

It is worth noting that countries such as Finland, Argentina and Poland showed percentages of female authorships above 50\%. Brazil and some Mediterranean countries, such as Italy, Spain and Portugal (included in the Others category), present rates of female participation above $40 \%$. At the other extreme, Japan stands out for its low female participation in neuroscience publications $(18.2 \%)$. This low percentage coincides with its quite low female presence in science in general, according to Larivière et al. (2013), who found a female authorship percentage of $16 \%$ in Japan.

It is worth to note that authorships are not the same as individuals (authors) because an individual can publish several papers. Our database included authors' full names and also surnames and affiliations. We assumed that two or more records (authorships) with the same name and surname belonged to the same individual (author). If necessary, the affiliation was consulted. The 35,776 male authorships corresponded to 20,928 different individuals (men), and the 17,575 female authorships corresponded to 12,824 individuals (women). For each author (individual), we obtained the number of papers published by that author, and then all the authors were separated by gender (males, females) in order to perform a between-subjects one-way ANOVA. Men yielded a mean productivity of 1.71 papers/author $(\mathrm{SD}=1.71), 95 \%$ CI $[1.69,1.73]$, and women yielded a mean productivity of 1.37 papers/author $(\mathrm{SD}=0.97), 95 \% \mathrm{CI}[1.35,1.39]$. The analysis of variance showed that the difference between male and female productivity was significant, although the effect size was small, $\mathrm{F}(1,33,750)=420.09, \mathrm{MS}_{\mathrm{e}}=2.18, \mathrm{p}<0.0001, d=0.245$.

As usual in science, Neuroscience publications are not evenly distributed among all authors. Table 3 presents the productivity of authors publishing in Neuroscience journals separated by gender. In bibliometric studies, the empirical distribution of author productivity is often compared to Lotka's law (Lotka, 1926). According to this law, the number of authors contributing with $n$ publications to a journal or a science field is about $1 / \mathrm{n}^{\mathrm{b}}$ of those making one single contribution (where b nearly equals 2 ). This means that about $63 \%$ of all authors will have just one publication, $16 \%$ will have two publications, $7 \%$ will have three publications, etc. However, the b exponent can vary depending on several factors that may affect the shape of the distribution (Pao, 1985). Our distribution of male authors fits Lotka's law when $b$ is equal to $2.91\left(\mathrm{R}^{2}=0.95\right)$; and the female distribution fits well when $\mathrm{b}$ is equal to $3.37\left(\mathrm{R}^{2}=0.98\right)$, which suggests that the distance between prolific and non-prolific authors is greater in women than in men.

\subsection{Collaboration}

Collaboration among researchers has increased considerably in science in recent decades (OECD, 2015b; UNESCO, 2015), and one of the indicators most frequently used to measure scientific collaboration is co-authorship, when a researcher writes a scientific document with another researcher/s. The sample of 11,590 papers (articles and reviews) from the Neuroscience journals analyzed in the present study (2009-2010) were signed, on average, by 5.78 authors per paper, considering all authorships (known and unknown gender). After selecting the authorships with known gender, the collaboration index for men was 3.09 authorships/ paper, whereas for women it was 1.52 authorships/paper. This difference is logical because there are fewer female authorships to be divided by the same denominator.

Table 4 shows the number of authorships/paper separated by gender. The calculation procedure was the following. First, the papers with a single authorship were selected from the entire sample of neuroscience papers, and subsequently the percentages of male and female authorships in this subsample were calculated. Next, the papers with two, three, or more authorships were successively selected, and again the percentages of male and female authorships were computed for each subsample. Table 4

\footnotetext{
${ }^{1}$ Regarding the number of papers, out of a total of 11,590 papers, 11,288 papers (97.4\%) had at least one authorship with known gender (male or female); only 302 papers had no authorship with known gender.

${ }^{2}$ Most gender bibliometric studies are based on an entire count (one contribution per authorship in each paper). If our data are computed in a fractional way (in each paper, the fractional contribution of each authorship is calculated by dividing by the total number of authorships in that paper), the results are not very different: the fractional contribution of men and women is $68.8 \%$ and $31.2 \%$, respectively.

${ }^{3}$ In other words, the difference between the observed frequencies $(35,776$ males, 17,575 females) and the expected frequencies if there were no gender differences - null hypothesis- (26675.5 males, 26675.5 females), yielded $\chi^{2}(d f=1)=3,197.76 ; \mathrm{p}<0.0001$; Cramer's $V=0.173$.

${ }^{4}$ Some papers from Web of Science do not provide the institutional address information for some authors (C1 field). In these cases, the information provided by the RP field (Reprint Address) was used.
} 
Table 2

Number and percentage of authorships in Neuroscience distributed by gender and geographical location and sorted by total number of authorships in descending order.

\begin{tabular}{|c|c|c|c|c|c|c|}
\hline $\begin{array}{l}\text { Geographical } \\
\text { location }\end{array}$ & $\begin{array}{l}\text { Total } \\
\text { Authorships }\end{array}$ & $\begin{array}{l}\text { Total (known } \\
\text { gender) }\end{array}$ & $\begin{array}{l}\text { Male } \\
\text { Authorships }\end{array}$ & $\%$ & $\begin{array}{l}\text { Female } \\
\text { Authorships }\end{array}$ & $\%$ \\
\hline USA & 29,300 & 23,195 & 15,661 & 67.5 & 7534 & 32.5 \\
\hline (European Union) $^{\mathrm{a}}$ & $(25,001)$ & $(21,516)$ & $(14,165)$ & $(65.8)$ & $(7351)$ & $(34.2)$ \\
\hline Germany & 6775 & 6049 & 4416 & 73.0 & 1633 & 27.0 \\
\hline United Kingdom & 5704 & 4912 & 3351 & 68.2 & 1561 & 31.8 \\
\hline France & 3058 & 2573 & 1571 & 61.1 & 1002 & 38.9 \\
\hline Canada & 2971 & 2443 & 1633 & 66.8 & 810 & 33.2 \\
\hline Japan & 2912 & 1937 & 1584 & 81.8 & 353 & 18.2 \\
\hline Italy & 2385 & 2104 & 1103 & 52.4 & 1001 & 47.6 \\
\hline Netherlands & 2030 & 1632 & 1111 & 68.1 & 521 & 31.9 \\
\hline Spain & 1529 & 1350 & 761 & 56.4 & 589 & 43.6 \\
\hline Australia & 1289 & 1103 & 734 & 66.5 & 369 & 33.5 \\
\hline Switzerland & 1188 & 1051 & 732 & 69.6 & 319 & 30.4 \\
\hline Peoples R China & 1148 & 306 & 185 & 60.5 & 121 & 39.5 \\
\hline Belgium & 737 & 624 & 410 & 65.7 & 214 & 34.3 \\
\hline Sweden & 687 & 564 & 372 & 66.0 & 192 & 34.0 \\
\hline South Korea & 652 & 133 & 98 & 73.7 & 35 & 26.3 \\
\hline Israel & 591 & 430 & 266 & 61.9 & 164 & 38.1 \\
\hline Finland & 543 & 379 & 169 & 44.6 & 210 & 55.4 \\
\hline Denmark & 360 & 291 & 223 & 76.6 & 68 & 23.4 \\
\hline Austria & 345 & 314 & 230 & 73.2 & 84 & 26.8 \\
\hline Norway & 312 & 271 & 172 & 63.5 & 99 & 36.5 \\
\hline Brazil & 245 & 212 & 119 & 56.1 & 93 & 43.9 \\
\hline Ireland & 231 & 205 & 137 & 66.8 & 68 & 33.2 \\
\hline Hungary & 155 & 136 & 104 & 76.5 & 32 & 23.5 \\
\hline Argentina & 151 & 141 & 62 & 44.0 & 79 & 56.0 \\
\hline Poland & 129 & 106 & 44 & 67.5 & 62 & 58.5 \\
\hline Others & 1510 & 890 & 528 & 59.3 & 362 & 40.7 \\
\hline
\end{tabular}

${ }^{\mathrm{a}}$ Data obtained by adding the data from all the countries of the European Union, including the European countries contained within the Others category.

Table 3

Productivity of authors publishing in Neuroscience journals (2009-2010) separated by gender. The percentages are based on the total for each gender.

\begin{tabular}{|c|c|c|c|c|}
\hline Papers/Author & Men & $\%$ & Women & $\%$ \\
\hline 1 & 14,247 & 68.08 & 10,025 & 78.17 \\
\hline 2 & 3561 & 17.02 & 1858 & 14.49 \\
\hline 3 & 1435 & 6.86 & 519 & 4.05 \\
\hline 4 & 651 & 3.11 & 181 & 1.41 \\
\hline 5 & 386 & 1.84 & 118 & 0.92 \\
\hline 6 & 223 & 1.07 & 50 & 0.39 \\
\hline 7 & 131 & 0.63 & 29 & 0.23 \\
\hline 8 & 82 & 0.39 & 10 & 0.08 \\
\hline 9 & 68 & 0.32 & 11 & 0.09 \\
\hline 10 & 44 & 0.21 & 7 & 0.05 \\
\hline 11 & 23 & 0.11 & 3 & 0.02 \\
\hline 12 & 21 & 0.10 & 5 & 0.04 \\
\hline 13 & 8 & 0.04 & 2 & 0.02 \\
\hline 14 & 7 & 0.03 & 1 & 0.01 \\
\hline 15 & 7 & 0.03 & 2 & 0.02 \\
\hline 16 & 5 & 0.02 & 3 & 0.02 \\
\hline 17 & 5 & 0.02 & & \\
\hline 18 & 2 & 0.01 & & \\
\hline 19 & 4 & 0.02 & & \\
\hline 20 & 3 & 0.01 & & \\
\hline 21 & 1 & 0.00 & & \\
\hline$<21$ & 14 & 0.07 & & \\
\hline
\end{tabular}

shows the low rate of female single-author papers $(20.5 \%$; 68 out of a total of 332 single-author papers) compared to the overall percentage of female authorship (32.9\%); by contrast, the percentage of single-author male authorships was $79.5 \%(264$ out of a total of 332 single-author papers), which is larger than the overall percentage of male authorships (67.1\%). The Chi square test between single authorships (264 males; 69 females) and overall authorships (35,776 males, 17,575 females) yielded $\chi^{2}(1)=23.22 ; \mathrm{p}<0.0001$; Cramer's $V=0.021$. Furthermore, the gender asymmetry depended on the type of document (article vs. reviews), as it was greater in the case of reviews. The overall percentage of reviews is actually very low (13.5\%), but within the subsample of single-author papers, the percentage of reviews rises to $65.7 \%$. A large proportion of reviews were published in 
Table 4

Number of authorships per paper in Neuroscience journals (2009-2010). Data separated by gender.

\begin{tabular}{|c|c|c|c|c|}
\hline Authorships/paper & Male Authorships & $\%$ & Female Authorships & $\%$ \\
\hline 1 & 264 & 79.5 & 68 & 20.5 \\
\hline 2 & 1901 & 73.1 & 701 & 26.9 \\
\hline 3 & 2863 & 71.4 & 1144 & 28.6 \\
\hline 4 & 3501 & 69.6 & 1529 & 30.4 \\
\hline 5 & 3759 & 67.4 & 1816 & 32.6 \\
\hline 6 & 3828 & 66.7 & 1913 & 33.3 \\
\hline 7 & 3582 & 65.5 & 1888 & 34.5 \\
\hline 8 & 2961 & 65.9 & 1533 & 34.1 \\
\hline 9 & 2721 & 66.3 & 1386 & 33.7 \\
\hline 10 & 2091 & 65.7 & 1091 & 34.3 \\
\hline$<10$ & 8305 & 64.8 & 4506 & 35.2 \\
\hline
\end{tabular}

journals with a high impact factor (Nature Reviews Neuroscience, Trends in Cognitive Sciences, Annual Review of Neuroscience, Nature Neuroscience, etc.), and, as discussed below in the Impact section, these influential reviews present greater gender asymmetry.

However, in papers with more than one authorship, female participation increases in relative terms. Table 4 reveals that there is an increase in the percentage of women's participation as the number of contributing authors in the paper increases, reaching $35.2 \%$ of female authorship in papers written by more than ten authors; indeed, the Pearson correlation between the number of authorships/paper $(1-10)$ and the percentage of female authorships is $r=0.869$ (significant at $p<0.001$ ).

Another interesting point examined in the present study is the collaboration pattern of men and women at both national and international levels. After excluding the documents signed by a single author, all the papers were classified as stemming from national vs. international collaborations. National collaboration was considered when all the affiliation addresses of a given paper belonged to a single country; international collaboration was considered when two or more affiliation addresses of a given paper belonged to different countries. Within the subset of national papers (7462), the percentages of male and female authorships were $66.4 \%$ (20,520 authorships) and 33.6\% (10,385 authorships), respectively. Within the subset of international papers (3749), the percentages of male and female authorships were $68.4 \%$ (14,618 authorships) and $32.0 \%$ (6881 authorships), respectively. This relative difference was significant although with a very small effect size, $\left(\chi^{2}(1)=14.63 ; p<0.0001\right.$; Cramer's $\left.V=0.017\right)$; that is, female participation is slightly lower in the publications resulting from an international collaboration than in the publications resulting from a national collaboration, in line with Lariviere et al's (2013) data (see also Abramo, D'Angelo, \& Murgia, 2013).

Finally, our study examined the author order in the by-line of each paper. Following the procedure introduced by Kretschmer, Kundra, Beaver and Kretschmer (2012), the concentrations of females (COF) and males (COM) in each position of the by-line were calculated. After excluding the single-author papers, the COF for each position was defined as the ratio between the percentage of females in that specific position and the overall percentage of female authorships. In the same way, the COM of each position was defined as the ratio between the percentage of males in that specific position and the overall percentage of male authorships. The results are displayed in Fig. 1. Interestingly, in relative terms women are clearly overrepresented in the first position of multi-author papers, which means that within the overall female percentage (one third of total authorships), women tend to be concentrated in the first position of the by-line. This could be a reflection of new female incorporations into

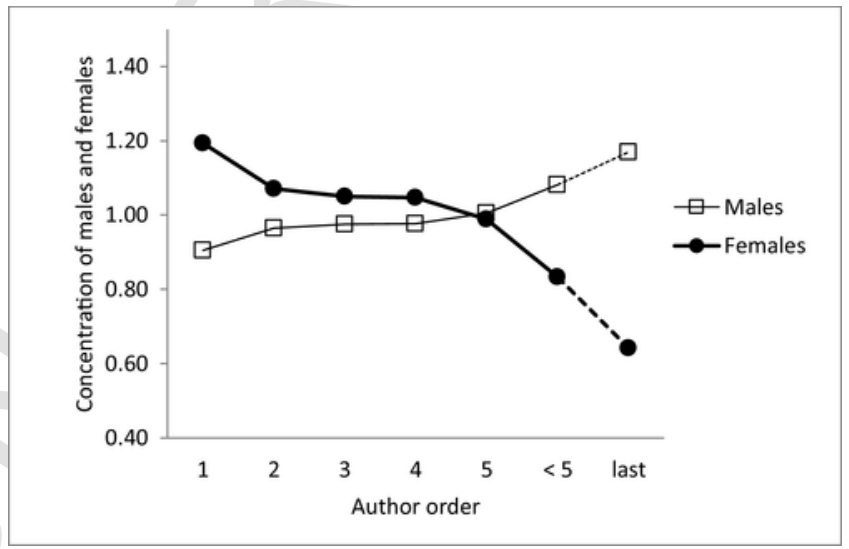

Fig. 1. Concentration values of males and females as a function of author order in the by-line of each Neuroscience paper (single-author papers excluded). Last position values are calculated for papers with at least three co-authors. 
neuroscience research publishing their first studies under the direction of a senior researcher (last position in the by-line). Continuing with this idea, women are clearly underrepresented in the last position of the by-line. In many scientific fields, including biosciences, the last author position of a paper is a key position occupied by the leading member of the research group. This is especially the case for articles with three or more co-authors (West et al., 2013). Consequently, we have calculated the COF and COM values at the last position for all papers with at least three co-authors. Our double pattern of relative overrepresentation of women in the first author position and relative underrepresentation of women in the last author position could suggest, as we will discuss further, that age probably plays a role in explaining gender asymmetry.

In addition, we found that the collaborative pattern was different depending on which gender occupied the first and last positions in the paper by-line. Within the set of multi-authored papers signed by a man in the first position, the percentages of male and female authorships were 76.4\% (19,916 male authorships) and 23.6\% (6166 female authorships), respectively. However, within the set of multi-authored papers signed by a woman in the first position, the corresponding percentages were $52.5 \%(9623$ male authorships) and 47.5\% (8690 female authorships). This difference of proportions resulted significant, $\left(\chi^{2}(1)=2739.82\right.$; $\mathrm{p}<0.0001$; Cramer's $V=0.248$ ). In a similar way, within the set of multi-authored papers signed by a man in the last position, the percentages of male and female authorships were $72.4 \%$ (27,065 male authorships) and 27.6\% (10,333 female authorships), respectively. However, if the papers are signed by a woman in the last position, the male authorships (46.6\%: 4624 male authorships) are outweighed by the female authorships (53.4\%, 5293 female authorships). This difference of proportions was significant, $\left(\chi^{2}(1)=2348.53 ; p<0.0001\right.$; Cramer's $V=0.223$. It seems that senior female researchers tend to establish scientific partnerships with other women more than male seniors do; or perhaps they work on subtopics that are relatively more appealing to scientific women.

\subsection{Research content}

Revisiting Table 2, we can see the journals that present a higher participation of female authorship: Frontiers in Neuroendocrinology (48.2\%, near gender parity), Journal of Pineal Research (42.6\%), and Glia (40.8\%). Apparently these journals are devoted to more "medical" subjects (e.g., relation between endocrinology and the nervous system, research on the pineal gland and its hormonal products, anatomy and physiology of the glia cells, etc.). In the other extreme, we find Annual Review of Neuroscience with only $13.6 \%$ of female authorships and Behavioral and Brain Sciences with a scarce $15.2 \%$. In general, journals with a strong theoretical component or specialized in reviewing and discussing the significant developments in the field (the two previous journals and Nature Reviews Neuroscience, Trends In Cognitive Sciences, Trends in Neurosciences, Current Opinion in Neurobiology) present a percentage of female participation quite below the overall mean. Authors who publish papers in these journals tend to be prestigious researchers with a consolidated (and presumably long) career. This fact is coherent with a small proportion of women found in the senior (last) position of the authorship by-lines, which, as discussed beñow, is consistent with the hypothesis that age probably plays a role in explaining the gender asymmetry in high-impact neuroscience.

In order to carry out a more fine-grained analysis of the scientific content, a keyword analysis was conducted on the papers of our sample. It should be noted that in addition to the keywords proposed by the authors themselves; Thomson Reuters has included a new field in recent years (Keywords Plus); providing additional keywords to expand the search in the database (see Zhang et al., 2016; for a comparative study). We followed a similar procedure as reported in previous bibliometric studies (González \& Cervera, 2016; González \& Palomar, 2014) and extracted the Keywords Plus (ID field in WoS) for each publication and separated by the gender of the authors occupying key positions in the document by-line.

Table S5 (see Supplemental Material) presents the top 25\% of Keywords Plus extracted from all papers of our sample separated by the gender of the authors occupying the first or last position in the authorship by-line. The keywords are sorted by absolute frequency in descending order and they have been distributed according to their relative percentages for comparative purposes (grouped in steps of 5\%). To identify changes, the terms that rise one or more steps when going from male to female authorships have been written in bold letters; conversely, the terms that descend one or more steps when going from male to female authorships have been underlined. Apparently, it seems difficult to find an overall pattern of terms selectively associated to female (or male) authorships. Beyond some changes of positions for several terms related to different anatomical structures, it is remarkable that the keyword 'children' rises a relative position when going from male to female authorships, and the same occurs with a set of terms related to psychological research on cognitive and emotional processes, such as: 'perception', 'recognition memory', ‘episodic memory', 'facial expressions', 'individual-differences', 'response-inhibition', 'social cognition', and also the keywords 'stress', 'mood disorders' and 'deficit hyperactivity disorder'.

\subsection{Scientific impact}

If we revisit Table 1, keeping in mind that the journals are sorted in descending order by their impact factor in the Journal Citation Reports (Journal Citation Reports (JCR) Edition, 2014), it is evident that most of the first journals in this ranking present a percentage of female participation below the overall female percentage $(32.9 \%)$. In fact, the Pearson correlation coefficient between the journal impact factors and their percentages of female authorships is negative and significant $(\mathrm{r}=-0.576, \mathrm{p}<0.001)$. Fig. 2 shows the regression plot of percentages of female authorship as a function of the impact factor (Journal Citation Reports (JCR) Edition, 2014) of the selected journals, and the regression line shows a negative slope (regression coefficient $=-0.736$ ). 


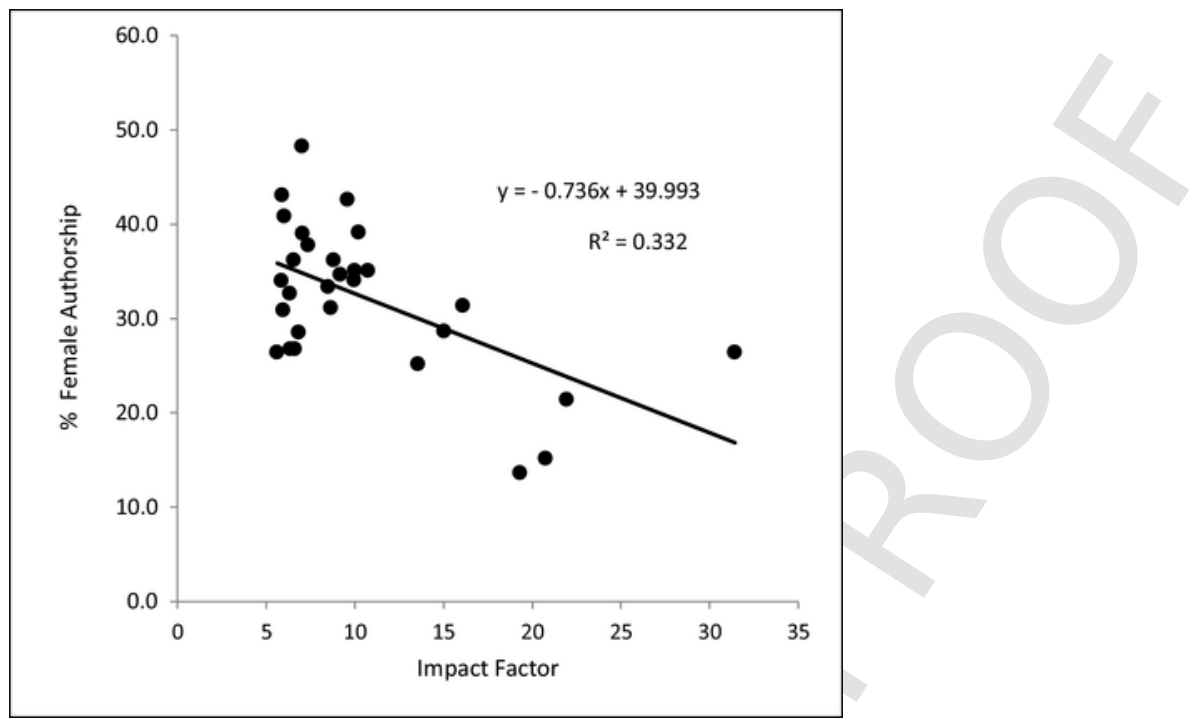

Fig. 2. Regression plot of percentages of female authorship as a function of the impact factor (Journal Citation Reports (JCR) Edition, 2014) of the 29 Neuroscience journals studied.

Using the SJR (SCImago Journal Rank; available at http://www.scimagojr.com/) as a measure of the scientific influence of each of the 29 journals studied, a negative correlation is also obtained with the $\%$ of female authorship $(r=-0.475, p<0.001)$.

The number of citations that each paper received (TC, Times Cited) was extracted and subsequently assigned to every authorship of that paper; then all authorships were separated by gender (males, females) in order to perform a between-subjects one-way ANOVA. Overall, males received an average of 51.36 citations/authorship $(S D=59.98), 95 \%$ CI $[50.74,51.98]$, and females received an average of 48.78 citations/authorship $(S D=52.63) 95 \%$ CI $[48.00,49.57]$. This citation difference was significant, although the effect size was very small, $F(1,53,350)=23.67, M S_{\mathrm{e}}=3,325.1, \mathrm{p}<0.0001, d=0.046$. Regarding the type of document, reviews received many more citations (76.83 citations/authorship) than regular articles (47.36 citations/authorship), as expected. Once again, gender differences emerged for both types of papers, although the effect sizes were quite small. Within the set of reviews, the overall means were 81.09 citations/authorship ( $S D=102.67), 95 \%$ CI $[77.34,84.84]$ for males, and 72.59 citations/authorship $(S D=89.34), 95 \%$ CI $[67.80,77.38]$ for females; $F(1,4214)=6.80, M S_{\mathrm{e}}=9728.1$, $p=0.009, d=0.088$. Within the set of regular articles, the citation difference, although significant, was quite small: 48.76 citations/authorship $(S D=53.92), 95 \%$ CI $[48.18,49.34]$ for males, and 46.81 citations/authorship $(S D=47.85), 95 \%$ CI [46.07, 47.55] for females; $\mathrm{F}(1,49134)=15.26, \mathrm{MS}_{\mathrm{e}}=2703.1, \mathrm{p}<0.0001, d=0.038$.

Reviews (1563) are a small part of the total number of papers $(11,590)$. In a second step, we excluded the review documents and computed citations received only by the regular articles. In a similar way to Larivière et al. (2013), we distinguished between multi-authored papers resulting from national vs. international collaborations (see the Collaboration section above). Fig. 3 displays the citation averages of Neuroscience articles with men and women in key positions of the by-line: single author, first author (of multi-authored articles), and last author (of multi-authored articles). The first point worth noting is that single-author articles written by a man or a woman received a similar number of citations: 33.75 vs. 33.43 citations, respectively; a between-subjects one-way ANOVA yielded no statistically significant differences between genders, $\mathrm{F}(1,112)<1, \mathrm{p}=0.978$. As expected, articles resulting from international collaborations were more visible and globally received more citations (51.94) than those resulting from national collaborations (44.13).

Within the set of national-collaboration articles, those in which a female occupied the first or the last position of the by-line were slightly less cited that articles in which a male occupied these positions. Data for the first author position were: 43.87 citations/article $(\mathrm{SD}=50.46), 95 \% \mathrm{CI}[42.07,46.67]$ for males in the first position vs. 39.95 citations/article $(\mathrm{SD}=41.64), 95 \%$ CI $[38.12,41.78]$ for females in the first position; $\mathrm{F}(1,5004)=8.28, \mathrm{MS}_{\mathrm{e}}=2222.7, \mathrm{p}=0.004, d=0.085$. Data for the last author position in the by-line were: 42.52 citations/article ( $\mathrm{SD}=45.07), 95 \% \mathrm{CI}[41.18,43.87]$ for males in the last position vs. 39.34 citations/article $(\mathrm{SD}=40.73), 95 \%$ CI $[37.00,41.68]$ for females in the last position; $\mathrm{F}(1,5479)=4.74, \mathrm{MS}_{\mathrm{e}}=1952.3$, $\mathrm{p}=0.030, d=0.074$. These differences were significant but quite small in terms of effect size.

Within the set of international-collaboration articles, the gender difference was only significant for the last position. Data for the first position were: 49.34 citations/article $(\mathrm{SD}=62.19), 95 \%$ CI $[46.02,52.48]$ for males in the first position vs. 47.02 citations/article $(\mathrm{SD}=42.21), 95 \% \mathrm{CI}[44.42,49.62]$ for females in the first position; this difference was not significant, $\mathrm{F}(1$, $2525)=1.08, \mathrm{MS}_{\mathrm{e}}=3027.5, \mathrm{p}=0.299, d=0.044$. Data for the last position were: 49.79 citations/article $(\mathrm{SD}=57.34), 95 \% \mathrm{CI}$ [47.41, 52.17] for males in the last position vs. 42.48 citations/article $(\mathrm{SD}=38.37), 95 \% \mathrm{CI}[39.27,45.69]$ for females in the last 


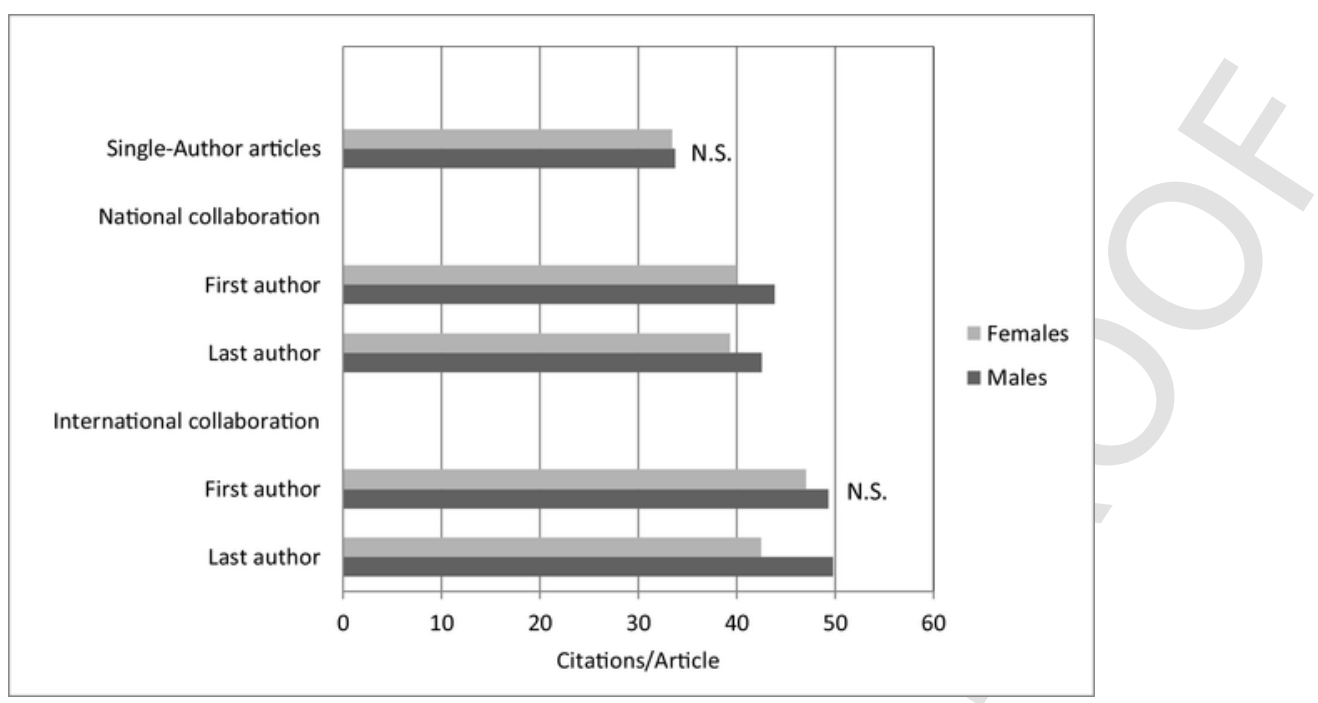

Fig. 3. Averages of number of citations received by Neuroscience articles (no reviews) with males and females in key positions of the by-line (single author, first author, last author). Multi-authored articles are separated between those resulting from national or international collaborations. N.S.: gender difference in citations non-significant.

position; $\mathrm{F}(1,2786)=8.07, \mathrm{MS}_{\mathrm{e}}=2929.7, \mathrm{p}=0.005, d=0.150$; this difference was significant and larger than the others in relative terms.

\section{Discussion and conclusions}

We examined the authorships of the reviews and articles published in 2009-2010 in the 29 journals with the highest impact within the NEUROSCIENCES category of the Journal Citation Reports (Journal Citation Reports (JCR) Edition, 2014), and we observed that about one third of them (32.9\%) corresponded to women. This female percentage is slightly higher than the global percentage obtained for overall scientific production. The last UNESCO Science Report (UNESCO, 2015) states that $28 \%$ of researchers are women. In a large-scale bibliometric analysis involving more than 27 million authorships worldwide across all scientific disciplines, Cassidy Sugimoto and colleagues (Larivière et al., 2013) found that women accounted for fewer than 30\% of them. West et al. (2013) analyzed a subsample of 1.8 million science and humanities papers extracted from the JSTOR corpus, and they obtained an overall $21.9 \%$ of female authorships. It is clear that despite the advances made by women in scientific research in recent decades, a high degree of gender inequality still persists today.

The scientific literature shows that this pattern of gender imbalance can vary across different fields. Recently, Cavero et al. (2015) analyzed the evolution of women participation in Computing research since its beginnings, and they observed a growth from $<3 \%$ of all academic publications in 1966, to about $16.3 \%$ in 2010. Sotudeh \& Khoshian (2014) studied women's scientific productivity in Nano Science \& Technology during 2005-2007, and they verified that the total number of female publications only accounted for $11.98 \%$ of all papers. In Software Engineering, Vela et al. (2012) reported that $17.2 \%$ of authors were female. Women's participation in the medical profession has increased in recent decades; however, after analyzing authorships from U.S. institutions in six very prominent medical journals during the 1970-2004 period, Jagsi et al. (2006) concluded that "over the past four decades, the proportion of women among both first and senior physician-authors of original research in the United States has significantly increased. Nevertheless, women still compose a minority of the authors of original research and guest editorials in the journals studied" (p. 281). Results from the extensive analysis by Larivière et al. (2013) confirmed previous findings and anecdotal observations that fields associated with 'care' (health, psychology, education) present less gender disparity than 'hard' sciences (high-energy physics, robotics, computer sciences, etc.). West et al.'s (2013) data follow along the same lines: their Table 1 shows the gender composition for disciplines within the JSTOR database (1990-2011), and the percentages of female authorships range from $10.64 \%$ in Mathematics, $12.04 \%$ in Philosophy, $13.68 \%$ in Economics, $18.11 \%$ in Probability-Statistics, ... to $37.57 \%$ in Pollution and occupational health, $41.41 \%$ in Sociology, $41.90 \%$ in Demography, and finally $46.35 \%$ in Education. It is worth noting that our average of $32.9 \%$ female authorships within the Neuroscience journals is located between the two extremes, quite close to the Cognitive Sciences percentage (32.12\%) from West et al. (2013).

The pattern of female collaboration in neuroscience publications is less international than male collaboration, in agreement with Larivière et al.'s (2013) findings for science overall, although this difference is smaller in our case. We also looked at the gender composition of each authorship position in the by-line of every neuroscience paper and found some interesting differences between men and women. It should be noted that the first and last author positions usually are key positions in the publications of many scientific fields, including biosciences and neuroscience, except in fields or subfields where the convention is for 
alphabetical order (e.g. mathematics). Ludo Waltman (2012) analyzed 24.8 million publications in all fields of science in the period 1981-2011 and found that the use of alphabetical authorship is declining over time. In 2011, less than 4\% of all publications presented their by-line in alphabetical order. The use of alphabetical authorship is most common in mathematics, economics, and also in high energy physics (typically with a very large number of authors). In our sample (Fig. 1), women are overrepresented in the first position of multi-author publications, which means that, within the overall female percentage representing half that of men, they tend to be concentrated in the first position of the paper by-line. This point is especially interesting because Cassidy Sugimoto and colleagues found -with important differences between fields- that women are much less likely to be listed as first author in research output worldwide (Larivière et al.'s, 2013). Our relative female overrepresentation in the first authorship position could be a reflection of new incorporations of women into neuroscience research -perhaps publishing their first postdoctoral papers. By contrast, women are clearly underrepresented in the last position of the by-line, usually a key position reserved for the senior or leading member of the research team. The relative underrepresentation of women in the last author position is a widespread fact observed in many scientific fields, including biosciences (Larivière et al., 2013), although not in mathematics or economics, for instance, in which the author order is alphabetical (Waltman, 2012). Our double pattern of relative overrepresentation of women in the first author position and relative underrepresentation in the last position suggests that age probably plays an important role in explaining the current gender imbalance in research production. This idea is reinforced by the asymmetries observed in the scientific impact. When the number of citations that each paper has received (TC field, or Times Cited) is extracted and subsequently assigned to each authorship, female researchers on average receive about 2.5 citations less than male researchers. This difference rises to 8.5 citations when considering only the reviews (without articles). Many reviews in our sample are single-author papers published in very high-impact journals and written by a senior researcher (Fig. 1). Curiously, when reviews are removed, the scientific impact of single-author regular articles is the same for men and women (Fig. 3). At the same time, the greatest asymmetry in the scientific impact of multi-authored articles is linked to the gender composition of the last/senior position in studies performed under international collaboration (Fig. 3). The current gender gap in neuroscience -and science in general- is a complex and multi-causal phenomenon, but evidence suggests that age undoubtedly plays a role. As Larivière et al. (2013) state, "the academic pipeline from junior to senior faculty leaks female scientists, and the senior ranks of science bear the imprint of previous generations' barriers to the progression of women. Thus it is likely that many of the trends we observed can be explained by the under-representation of women among the elders of science. After all, seniority, authorship position, collaboration and citation are all highly interlinked variables" (p. 213). For example, according with the US National Science Foundation (National Science Foundation (NSF), 2015; see also Hopkins, Jawitz, McCarty, Goldman, \& Basu, 2013), women are only slightly underrepresented among doctoral graduates at US universities, but they are importantly underrepresented in academic positions. A limitation of the present study is that we have not direct evidence to test the age hypothesis because the WoS database (and any other bibliographic database) does not provide data about the authors' age. Nevertheless, the larger gender asymmetry observed in the number of reviews is also coherent with this hypothesis. Reviews published in high-impact journals are usually written by reputable and influential researchers that typically occupy senior positions as leaders of research teams. In some way, the age story is a hopeful story since it implies that (at least a part of) gender inequality in science will tend to vanish in the near future. Some data point in that direction. Thus, Van Arensbergen, Van der Weijden, \& Van den Besselaar (2012) recently compared male and female researchers using data on research grant applications in the Netherlands, and they concluded that gender differences in terms of publications and citations are disappearing in the younger generation of scientists (see also Marsh, Jayasinghe, \& Bond, 2011; Rørstad \& Aksnes. 2015).

In summary, women have been contributing in a significant way to the development of neurosciences (Finger, 2002), and their participation in the past few decades has increased impressively (Haak, 2002). According to the Society for Neuroscience $(\mathrm{SfN})$, women have had an increasing presence within the field, going from being $21 \%$ of SfN members in 1982 to $43 \%$ in 2011 . However, despite their progress, it can be concluded that women still have not achieved a proportionate level of relevance in neuroscience research output. As mentioned above, one of reasons for this asymmetry probably has to do with age, and part of the imbalance will be corrected in the coming years, but surely other forces continue to act in the opposite direction -differential investment in family and childcare, subtle gender bias, etc. It is important, therefore, to continue the SfN policy of increasing the opportunities "to highlight the scientific excellence of women neuroscientists, address the challenges women may confront in academic and other professional settings, educate about and overcome gender-bias, and advance training opportunities for women" (SfN, Women in Neuroscience, https://www.sfn.org/careers-and-training/women-in-neuroscience.)

\section{Funding}

This work was supported by the Spanish Ministry of Economy and Competitiveness (Research Grant FFI2014-54088-P).

\section{Authors' Contributions}

Julio González-Álvarez: Conceived and designed the analysis; collected the data; contributed data or analysis tools; preform analysis; wrote paper.performed statistical analysis;

Teresa Cervera-Crespo: conceived and designed the analysis; contributed data or analysis tools; wrote Paper. 


\section{Appendix A. Supplementary data} 007.

Supplementary data associated with this article can be found, in the online version, at http://dx.doi.org/10.1016/j.joi.2016.12.

\section{References}

Abramo, G., D'Angelo, C.A., Murgia, G., 2013. Gender differences in research collaboration. Journal of Informetrics 7 (4), 811-822. http://dx.doi.org/10.1016/j. joi.2013.07.002.

Bala, A., Gupta, B.M., 2010. Mapping of Indian neuroscience research: A scientometric analysis of research output during 1999-2008. Neurology India 58 (1), 35-41. http://dx.doi.org/10.4103/0028-3886.60393.

Barrios, M., Villarroya, A., Borrego, A., 2013. Scientific production in psychology: A gender analysis. Scientometrics 95 (1), 15-23. http://dx.doi.org/10.1007/ s11192-012-0816-4.

Berardelli, A., Barberini, I., Defazio, G., Mancardi, G.L., Messina, C., 2005. Neurological research in Italy in 2003 and 2004. Neurological Sciences 26 (4), 189-193. http://dx.doi.org/10.1007/s10072-005-0475-9.

Cavero, J.M., Vela, B., Cáceres, P., Cuesta, C., Sierra-Alonso, A., 2015. The evolution of female authorship in computing research. Scientometrics 103 (1), 85-100. http://dx.doi.org/10.1007/s11192-014-1520-3.

Cohen, J., 1988. Statistical power analysis of the behavioral sciences, 2nd ed. Academic Press, New York.

European Commission, 2013. She Figs. 2012 - Gender in research and innovation. [EU Commission - Working Document]. http://dx.doi.org/10.2777/38520.

European Commission, 2016. She Figs. 2015 - Gender in research and innovation. [EU Commission - Working Document]. http://dx.doi.org/10.2777/744106.

Finger, S., 2002. Women and the History of the Neurosciences. Journal of the History of the Neurosciences 11 (1), 80-86. http://dx.doi.org/10.1076/jhin.11.1.80. 9098.

Glänzel, W., Danell, R., Persson, O., 2003. The decline of Swedish neuroscience: Decomposing a bibliometric national science indicator. Scientometrics 66 (1), 199-218. http://dx.doi.org/10.1023/A:1024185601555.

González, J., Cervera, T., 2016. Contemporary psychology and women: A gender analysis of the scientific production. International Journal of Psychology [submitted].

González, J., Palomar, M.A., 2014. Twenty-two years of psychological science in Psychological Science. International Journal of Psychology 49 (1), 56-60. http: //dx.doi.org/10.1002/ijop.12009.

Gravetter, F.J., Wallnau, L.B., 2012. Statistics for the behavioral sciences, 9th ed. Wadsworth Publishing Company, Belmont, CA.

Haak, L., 2002. Women in neuroscience (WIN): the first twenty years. Journal of the History of the Neurosciences 11 (1), 70-79. http://dx.doi.org/10.1076/jhin. 11.1.70.9111.

Hopkins, A.L., Jawitz, J.W., McCarty, C., Goldman, A., Basu, N.B., 2013. Disparities in publication patterns by gender, race and ethnicity based on a survey of a random sample of authors. Scientometrics 96 (2), 515-534. http://dx.doi.org/10.1007/s11192-012-0893-4.

Jagsi, R., Guancial, E.A., Worobey, C.C., Henault, L.E., Chang, Y., Starr, R., et al., 2006. The gender gap in authorship of academic medical literature-a 35-year perspective. The New England Journal of Medicine 355 (3), 281-287. http://dx.doi.org/10.1056/NEJMsa053910.

Journal Citation Reports (JCR) Edition, 2014. Thomson Reuters.

Kretschmer, H., Kundra, R., Beaver, D., Kretschmer, T., 2012. Gender bias in journals of gender studies. Scientometrics 93 (1), 135-150. http://dx.doi.org/10. 1007/s11192-012-0661-5.

Larivière, V., Ni, C., Gingras, Y., Cronin, B., Sugimoto, C.R., 2013. Bibliometrics: global gender disparities in science. Nature 504 (7479), 211-213. http://dx. doi.org/10.1038/504211a.

Lotka, A.J., 1926. The frequency distribution of scientific productivity. Journal of the Washington Academy of Sciences 16, $317-323$.

Marsh, H.W., Jayasinghe, U.W., Bond, N.W., 2011. Gender differences in peer reviews of grant applications: A substantive-methodological synergy in support of the null hypothesis model. Journal of Informetrics 5 (1), 167-180. http://dx.doi.org/10.1016/j.joi.2010.10.004.

Mauleón, E., Bordon, M., 2006. Productivity, impact and publication habits by gender in the area of Materials Science. Scientometrics 66 (1), 199-218. http://dx. doi.org/10.1007/s11192-006-0014-3.

Moss-Racusin, C.A., Dovidio, J.F., Brescoll, V.L., Graham, M.J., Handelsman, J., 2012. Science faculty's subtle gender biases favor male students. Proceedings of the National Academy of Sciences 109 (41), 16474-16479. http://dx.doi.org/10.1073/pnas.1211286109.

National Science Foundation (NSF), 2015. Women, minorities, and persons with disabilities in science and engineering: 2015. Special reports. Available at: https: //www.nsf.gov/statistics/2015/nsf15311/.

Nature Neuroscience, 2006. Women in neuroscience: a numbers game. Editorial. Nature Neuroscience 9 (7), 853. http://dx.doi.org/10.1038/nn0706-853.

Organization for Economic Co-operation and Development. Education at a Glance 2015. 10.1787/eag-2015-en.

Organization for Economic Co-operation and Development. OECD Science, Technology and Industry Scoreboard. 10.1787/sti_scoreboard-2015-en.

Pao, M.L., 1985. Lotka law-A testing procedure. Information Processing and Management 21, 305-320.

Persson, O.D., Danell, R., Wiborg-Schneider, J., 2009. How to use Bibexcel for various types of bibliometric analysis. In: Astrom, F., Danell, R., Larsen, B., Schneider, J. (Eds.), Celebrating scholarly communication studies: A festschrift for olle persson at his 60th birthday. International Society for Scientometrics and Informetrics, Leuven, Belgium, pp. 9-24. Retrieved from http://www8. umu.se/inforsk/Bibexcel/.

Rørstad, K., Aksnes, D.W., 2015. Publication rate expressed by age, gender and academic position-A large-scale analysis of Norwegian academic staff. Journal of Informetrics 9 (2), 317-333.

SCImago (2007). SJR - SCImago Journal \& Country Rank. Retrieved September 10, 2015, from http://www.scimagojr.com.

Saha, S., Saint, S., Christakis, D.A., 2003. Impact factor: A valid measure of journal quality?. Journal of the Medical Library Association 91 (1), 42.

Shen, H., 2013. Inequality quantified: Mind the gender gap. Nature 495 (7439), 22-24. http://dx.doi.org/10.1038/495022a.

Sotudeh, H., Khoshian, N., 2014. Gender differences in science: the case of scientific productivity in Nano Science \& Technology during 2005-2007. Scientometrics 98 (1), 457-472. http://dx.doi.org/10.1007/s11192-013-1031-7.

UNESCO, 2015. United Nations Educational, Scientific and Cultural Organization UNESCO Science Report. Towatds. 2030.

Van Arensbergen, P., Van der Weijden, I., Van den Besselaar, P., 2012. Gender differences in scientific productivity: a persisting phenomenon?. Scientometrics 93 (3), 857-868. http://dx.doi.org/10.1007/s11192-012-0712-y.

Vela, B., Cáceres, P., Cavero, J.M., 2012. Participation of women in software engineering publications. Scientometrics 93 (3), 661-669. http://dx.doi.org/10.1007/ s11192-012-0774-x.

Waltman, L., 2012. An empirical analysis of the use of alphabetical authorship in scientific publishing. Journal of Informetrics 6 (4), 700-711. http://dx.doi.org/ 10.1016/j.joi.2012.07.008.

West, J.D., Jacquet, J., King, M.M., Correll, S.J., Bergstrom, C.T., 2013. The role of gender in scholarly authorship. PLoS One 8 (7), e66212. http://dx.doi.org/ 10.1371/journal.pone.0066212. 
Xu, W., Chen, Y., Shen, Z., 2008. Neuroscience output of China: A Medline based bibliometric study. Scientometrics 57 (3), 399-409. http://dx.doi.org/10.1023/ A:1025060819495.

Zhang, J., Yu, Q., Zheng, F., Long, C., Lu, Z., Duan, Z., 2016. Comparing keywords plus of WOS and author keywords: A case study of patient adherence research. Journal of the Association for Information Science and Technology 67, 967-972. http://dx.doi.org/10.1002/asi.23437. 